\title{
Neural Activation in the Olfactory Epithelium of East African Cichlid in Response to Odorant Exposure
}

\section{Authors}

Riki Kawamura ${ }^{1}$ and Masato Nikaido ${ }^{1 *}$.

${ }^{1}$ School of Life Science and Technology, Tokyo Institute of Technology

* Corresponding author: E-mail: mnikaido@bio.titech.ac.jp 


\section{Abstract}

Fish use olfaction to gain various information. To know what they receive and how they receive is vital for understanding the diversity of fish. However, studies on fish olfactory or pheromone receptors are still insufficient, and most of them are on a model organism. Here, we established an experimental system to detect a biological-derived neural response from the olfactory epithelium of East African cichlid, the most diversified fish lineage, by in situ hybridizations of $c$-fos. We first tested the response of microvillous neurons, which are expected to be dominated by $V 2 R$-expressing neurons, to several odorants. We showed that microvillous neurons responded to amino acids and food extraction, suggesting that fish receive amino acids via V2R receptors as food-related odorants. We next tested the response of each of the four subfamilies of V2R receptors, showing that two of four subfamilies responded to proteinogenic amino acids. Notably, individual paralogs in subfamily 14, which responded to arginine, had variability in receptivity to arginine, indicating the ligand differentiation in the cichlid-specifically expanded subfamily. Finally, we established a noninvasive method to collect urine and tested the response of putative pheromone receptor V1R to male urine, and we showed two V1R receptors responded to male urine. Furthermore, we showed V1R2 receptor responded to 4-hydroxyphenyl acetate and lithocholic acid. This study provides an experimental basis for the study of olfaction in East African cichlids related to its ecology and speciation. 


\section{Keyword}

c-fos, V1R, V2R, amino acid, urine collection

\section{Introduction}

Animals use olfaction in several situations, such as finding food, finding and judging mates, recognizing territories, migration, or detecting predators. Many olfactory or pheromone receptor genes in their genomes play a vital role in these behaviors. Hence, to understand their specific behavior, the receptor function must be revealed.

In fish, several soluble chemicals are detected by the olfactory epithelium (OE) as odor. Amino acids drive feeding behavior in several species (Valentinčič et al., 1999; Hara, 2006; Koide et al., 2009). Amino acids also work as migration pheromone or sex pheromone in salmonid species (Shoji et al., 2003; Yambe et al., 2006; Yamamoto et al., 2010, 2013). Polyamines, which are released from carrion, also drive feeding behavior in goldfish (Rolen et al., 2003), whereas they drive aversive behavior in zebrafish (Hussain et al., 2013). Nucleotides also drive feeding behavior (Wakisaka et al., 2017). Sex steroids, such as 17,20ß-dihydroxy-4-pregnen-3-one (17, $20 \beta$-P) or androstenedione, strongly induce EOG response and have a primer effect in goldfish (Sorensen et al., 1987, 2005; Stacey et al., 1989). Prostaglandins also work as a pheromone in goldfish and zebrafish (Sorensen et al., 1988; Yabuki et al., 2016). Moreover, bile acids are detected by several species, and they drive migration behavior in lamprey, although the functions in other fishes remain controversial (Li et al., 1995; Michel and Lubomudrov, 1995; Zhang et al., 2001; Huertas et al., 2010).

These odorants are detected by olfactory or pheromone receptors, which are encoded by four G protein-coupled receptor multigene families: odorant receptor (OR; Buck and Axel, 1991), trace amine-associated receptor (TAAR; Liberles and Buck, 2006), vomeronasal type-1 receptor (V1R, also termed as ORA; Dulac and Axel, 1995), and vomeronasal type-2 receptor (V2R, also termed as OlfC; Herrada and Dulac, 1997), in vertebrates including fishes. Respectively, OR or TAAR are 
expressed in ciliated neurons (Hansen et al., 2004; Sorensen and Sato, 2005), and V1R and V2R are expressed in microvillous neurons (Hansen et al., 2004; Sorensen and Sato, 2005), except single V1R (V1R3), which is expressed in crypt neurons (Oka et al., 2012). Ciliated neurons detect a broad range of odorants, such as amino acids, sex steroids, prostaglandins, and bile acids in several fishes (Sato and Suzuki, 2001; Hansen et al., 2003; Sato and Sorensen, 2018). Furthermore, studies on zebrafish deorphanized OR113 receptor as fish pheromone prostaglandin $\mathrm{F}_{2 \alpha}$ receptor (Yabuki et al., 2016), and several TAAR receptors as polyamine receptors (Hussain et al., 2009, 2013). Alternatively, microvillous neurons, which are expected to be dominated by V2R expressing neurons, specifically detect amino acids (Sato and Suzuki, 2001; Hansen et al., 2003; Sato and Sorensen, 2018). Many studies indicate that V2R receptors detect amino acids (Koide et al., 2009; DeMaria et al., 2013). Also, several heterologous expression experiments show that zebrafish V1R receptors bind 4hydroxyphenyl acetate (4HPAA) and bile acids (Behrens et al., 2014; Cong et al., 2019).

These studies are limited to the model organism zebrafish and several nonmodel organisms such as Salmon. Alternatively, Neoteleostei, which makes up approximately $60 \%$ of species within fish, are not focused on studies on olfaction. Studying these nonmodel organism species is crucial for understanding fish evolution.

In this study, we focused on cichlid, one of the most diversified lineages in vertebrates. Especially, cichlids in the East African Great Lakes are the most striking example of adaptive radiation (Kocher, 2004). Although visual sense was kept focused because of the highly diversified nuptial colouration, cichlid also uses olfaction in many different contexts (Keller-Costa et al., 2015). For example, Pseudotropheus emmiltos use olfaction for conspecific recognition (Plenderleith et al., 2005), and olfaction contribute to the sexual imprinting of Pundamilia species (Verzijden and Ten Cate, 2007). Other studies show that male tilapia evaluates the sexual status from female urine, and glucuronidated steroid in male urine works as a priming pheromone (Miranda et al., 2005; KellerCosta et al., 2014). Moreover, we previously found several highly diverse polymorphic alleles in the V1R receptors of East African cichlid (Nikaido et al., 2014), and the copy number of V2R receptors 
increased in East African cichlid (Nikaido et al., 2013).

Here, we have established an experimental system to detect a biological-derived neural response from olfactory sensory neurons of East African cichlid Haplochromis chilotes by in situ hybridizations using $c$-fos riboprobe (Figure 1). This experimental system tested the response of microvillous neurons, $V 2 R$-expression neurons, and $V 1 R$-expressing neurons to several odorants. Compared with previous studies on heterologous expression experiments, our experimental system can be tested on the biological-derived and can avoid difficulty in translocation of receptors to the cell surface. This study may provide a fundamental basis for the study of olfaction in East African cichlids. 


\section{Materials and Methods}

\section{Fish}

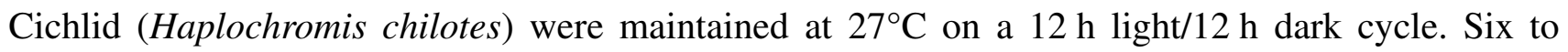
twelve individuals were kept in a plastic tank $(40 \mathrm{~cm} \times 25 \mathrm{~cm} \times 36 \mathrm{~cm})$. Mature adults were used for the experiment.

\section{Odorant solutions}

Twenty proteinogenic amino acids (arginine, histidine, lysine, aspartate, glutamate, serine, threonine, asparagine, glutamine, cysteine, glycine, proline, alanine, isoleucine, leucine, methionine, phenylalanine, tryptophan, tyrosine, and valine), 4HPAA, lithocholic acid (LCA) were purchased from Wako Pure Chemical Industries, Sigma Chemical Co. Each amino acid (except tyrosine) and 4HPAA was dissolved in ultrapure water to $12 \mathrm{mM}$. Tyrosine and LCA were dissolved in $6 \mathrm{mM}$ $\mathrm{NaOH}$ to $12 \mathrm{mM}$. Three conjugated steroids dehydroepiandrosterone 3-sulfate (DHEA-s), $\beta$-estradiol 17-( $\beta$-D-glucuronide) ( $\left.\mathrm{E}_{2}-17 \mathrm{~g}\right)$, and $\beta$-estradiol 3,17-disulfate $\left(\mathrm{E}_{2}-3,17 \mathrm{~s}\right)$ were respectively purchased from Tokyo Chemical Industry, Cayman Chemical Co., and Santa Cruz Biotechnology and dissolved in DMSO to $10 \mathrm{mM}$. Food extractions were prepared by adding ultrapure water up to $14 \mathrm{~mL}$ to $2 \mathrm{~g}$ of crushed fish food Otohime EP1 (Marubeni Nisshin Feed Co.). After waiting for $5 \mathrm{~min}$, the extraction liquid was centrifuged at $8,000 \times \mathrm{g}$ for $5 \mathrm{~min}$, and the supernatant was collected as food extraction stock. The stock was stored at $4{ }^{\circ} \mathrm{C}$ until the exposure experiment.

\section{Urine collection}

Urine was collected from mature male cichlid. Although several studies had collected nondiluted urine from fish, they were limited to some larger fish such as masu salmon, rainbow trout, Mozambique tilapia, and Senegalese sole (Yambe et al., 1999; Sato and Suzuki, 2001; Keller-Costa et al., 2014; Fatsini et al., 2017). Here, by referring to a method to collect urine from Masu salmon 
used in Yambe et al., 1999, we developed a noninvasive method to collect urine directly from cichlid, whose size is approximately 6-9 $\mathrm{cm}$ under swimming conditions (Figure 5B). We used a dental root canal cleaning probe needle $(28 \mathrm{G}, 490703$, BSA Sakurai Co.) to construct a sampling catheter (Figure 5A). This needle has a hole in the side near the needle's tip to prevent being clogged. Approximately $0.5-1.2 \mathrm{~cm}$ from the tip of this probe needle was gently bent approximately $90^{\circ}$ so that the hollow is not collapsed (Figure 5A). In the case of the female catheter, a silicone plug was further attached to the tip of the catheter (Figure 5A). This bent needle was connected to $15 \mathrm{~mL}$ centrifuge tube with a silicon tube (OD: $10 \mathrm{~mm}$, ID: $0.5 \mathrm{~mm}$ ) fixed with adhesive (Aron Alpha EXTRA Fast-Acting Versatile, Konishi) to trap the urine. The centrifuge tube was further connected to the aspirator (DAS-01, As one) to aspirate the urine.

Cichlid was anesthetized with ice water for $1 \mathrm{~min}$. The catheter was inserted via the urogenital papilla into the urinary bladder. The silicon tube connecting the catheter was fixed to the anal fin by wire and clip to be held in place. Catheterized cichlid was placed in the net chamber made from a pot bottom net to restrict the movement. Cichlid could accumulate for $15 \mathrm{~min}$. After aspirating for $3-5 \mathrm{~h}$, approximately $500-1000 \mu \mathrm{L}$ of urine was trapped into the centrifuge tube placed on ice. Urine collected during the first $30 \mathrm{~min}$ was discarded to prevent contamination by coelomic fluid. To ensure that the sample collected was urine, $10 \mu \mathrm{L}$ of the collected sample was used to verify the existence of ammonia by indophenol assay (Tetra Test Ammonia Reagent, Tetra).

All experimental studies using the animals were approved by the Institutional Animal Experiment Committee of the Tokyo Institute of Technology and conducted according to the institutional and governmental ARRIVE guidelines.

\section{Exposure and tissue preparation}

Adult cichlid was isolated to a glass tank $(40 \mathrm{~cm} \times 25 \mathrm{~cm} \times 36 \mathrm{~cm})$ the day before the exposure and was not fed. The next day, the fish was transferred to the exposure tank $(30 \mathrm{~cm} \times 11 \mathrm{~cm} \times 9 \mathrm{~cm}, 3 \mathrm{~L})$, covered with black paper to make the inside dark, and served with clean dechlorinated water. The 
fish was kept in this tank for 1.5-3 h before exposure. These procedures were performed to reduce the background expression of $c$-fos in the OE. The water supply was then stopped, and $15 \mathrm{~mL}$ of odorant solution was delivered to the tank using a peristaltic pump (SJ-1211II-H, Atto). Each solution was diluted with ultrapure water (the mixture of 20 amino acids/amino acids group A-D: $400 \mu \mathrm{M}$ each, the mixture of conjugated steroids: $6.6 \mu \mathrm{M}$ each, arginine/4HPAA: $2 \mathrm{mM}, \mathrm{LCA}: 4 \mathrm{mM}$, male urine: 30-fold dilution, food extraction: 75-fold dilution). Water was exposed in the control. After exposing the fish for $1 \mathrm{~min}$, the water was resupplied, and the fish was kept in the tank for 20 min for the expression of $c$-fos. The fish was then quickly decapitated, and the olfactory epithelia were dissected out in $4 \%$ paraformaldehyde (PFA, Wako)/0.7× phosphate-buffered saline (PBS). Dissected tissues were fixed in $4 \%$ PFA/0.7x PBS at $4{ }^{\circ} \mathrm{C}$ for $7.5 \mathrm{~h}$. Fixed tissues were treated with $20 \%$ sucrose $/ 0.7 \times$ PBS at $4^{\circ} \mathrm{C}$ overnight for cryoprotection before embedding. Tissues were embedded in the Tissue Tek O.C.T. compound (Sakura) and frozen using liquid nitrogen. Embedded tissues were sliced into a $10 \mu \mathrm{m}$ section in a horizontal direction and loaded on a glass slide (MAS01, Matsunami). Sections were kept at $-80^{\circ} \mathrm{C}$ until use for the following experiments.

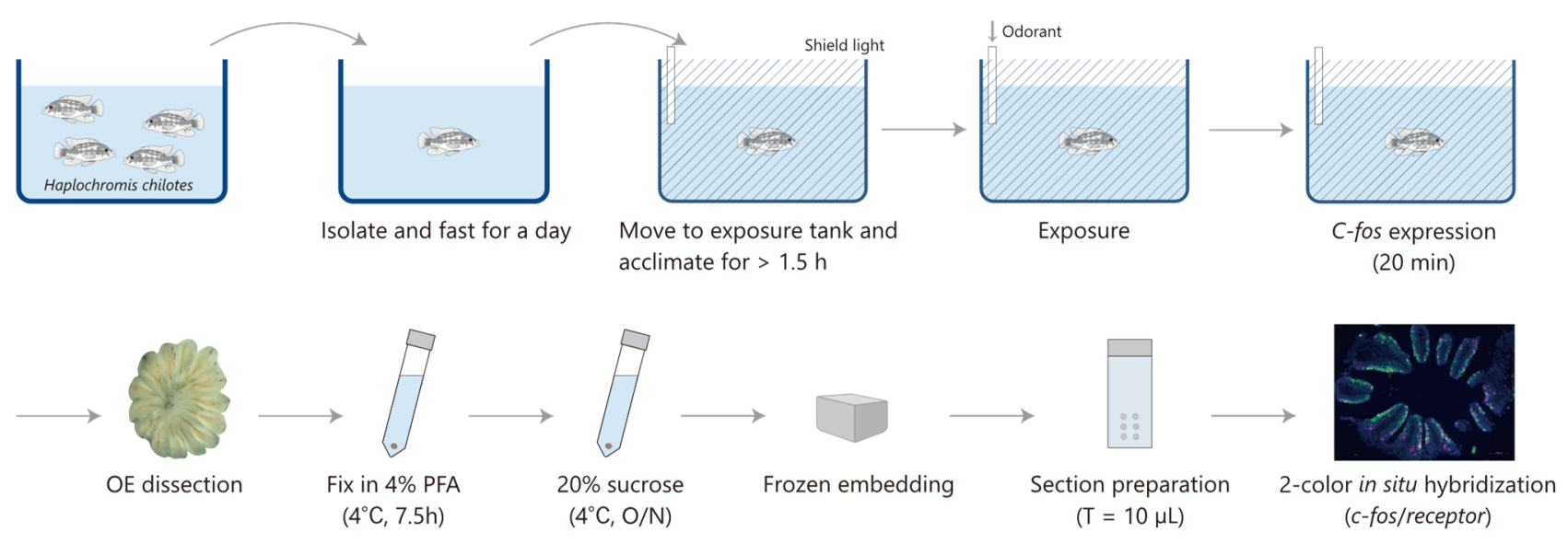

Figure 1. Schematic flow of the experiment. Cichlid was exposed to an odorant. Olfactory epithelia were then isolated, fixed, and frozen embedded. The section was prepared and used for in situ hybridization. 


\section{Preparation of riboprobes}

Riboprobes for in situ hybridization (ISH) were designed in the coding region or untranslated region. Each sequence was amplified from cDNA of OE by Ex-Taq (Takara) with primers listed in Supplementary Table 1. PCR products were ligated to pGEM-T (Promega) or pBluescript SKII (-) plasmid and sequenced. Plasmids were extracted with the QIAfilter Plasmid Midi Kit (QIAGEN) and then linearized using the appropriate restriction enzyme (Takara). Digoxigenin (DIG)-labeled or fluorescein (FITC)-labeled riboprobes were synthesized with T7 or T3 or SP6 RNA polymerase (Roche) from the linearized plasmids with DIG or FITC RNA labeling mix (Roche), respectively.

\section{In situ hybridization}

Single-colour and two-colour ISH were performed according to the method that is modified in a previous study (Suzuki et al., 2015). Briefly, in single-colour ISH, sections were hybridized with DIGlabeled riboprobes $(5 \mathrm{ng} / \mu \mathrm{g})$ at $60^{\circ} \mathrm{C}$ overnight and treated with POD-conjugated anti-DIG antibody (1:100, Roche). Signals were amplified by Tyramide Signal Amplification (TSA) Plus Biotin kit (PerkinElmer) and detected with Alexa Fluor 488-conjugated streptavidin (1:200, Thermo Fisher Scientific). Sections were enclosed with VECTASHIELD mounting medium with DAPI (Vector Laboratories). Double ISH sections were hybridized with DIG-labeled riboprobes and FITC-labeled riboprobe $\left(2.5 \mathrm{ng} / \mu \mathrm{g}\right.$ at each) at $60^{\circ} \mathrm{C}$ overnight and treated with peroxidase-conjugated anti-DIG antibody (1:100). Signals from DIG-riboprobes were amplified using TSA Plus DIG kit (PerkinElmer) and detected with DyLight 594-conjugated anti-DIG antibody (1:500, Vector Laboratories). Sections were treated with $15 \% \mathrm{H}_{2} \mathrm{O}_{2}$ in TBS for 30 min to inactivate peroxidase. A signal from FITC-labeled riboprobes was detected with an HRP-conjugated anti-FITC antibody (1:500, PerkinElmer). Signals were then amplified using TSA Plus Biotin kit (PerkinElmer) and detected with Alexa Fluor 488-conjugated streptavidin (1:200, Thermo Fisher Scientific). Sections were enclosed with VECTASHIELD mounting medium with DAPI (Vector Laboratories). All images were digitally captured using a fluorescence microscope (Carl Zeiss). 


\section{Quantification of neuron number}

The image was first integrated into a single section. The tone of the image was corrected by "Curves." Expressing neurons were determined using the threshold of brightness (85) and the shape and marked using the "Count Tool." The area measured by the DAPI image was used to correct the number of neurons. Colocalization was also tested on the marked neuron. These procedures were performed using Adobe Photoshop CC 2018. 


\section{Results}

\section{Cichlid $c$-fos has characteristics of an immediate-early gene}

In initial experiments, we exposed cichlid to food extraction and assessed the upregulation of five immediate-early genes $c$-fos, egrl, c-jun, fral, and junb by in situ hybridizations in the OE. By comparing the expression of nonexposed and exposed OE, we concluded that $c$-fos is the most suitable neural activity marker for cichlid OE (Figure 2A).

To quantitatively confirm the upregulation of $c$-fos in the cichlid OE, we exposed cichlid to food extraction and tested whether the number of $c$-fos-expressing neurons would increase with time (control/10/20/30 min) since exposure (Figure 2B, C, Supplementary Table 2). We compared the number of $c$-fos-expressing neurons in five sections that were evenly selected and found that the number in 20 and 30 min was significantly greater than that in control $(\mathrm{n}=3 ; p=0.029, p=0.043$; Tukey-Kramer test, Figure 1B). Since this experiment, we have set the time length between odorant exposure and ice anesthetizing as $20 \mathrm{~min}$. 


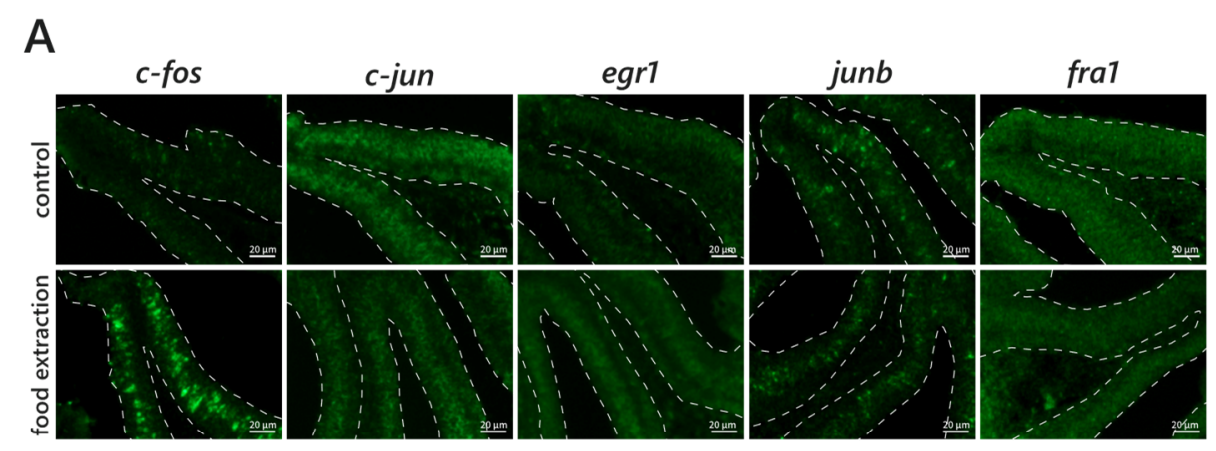

B
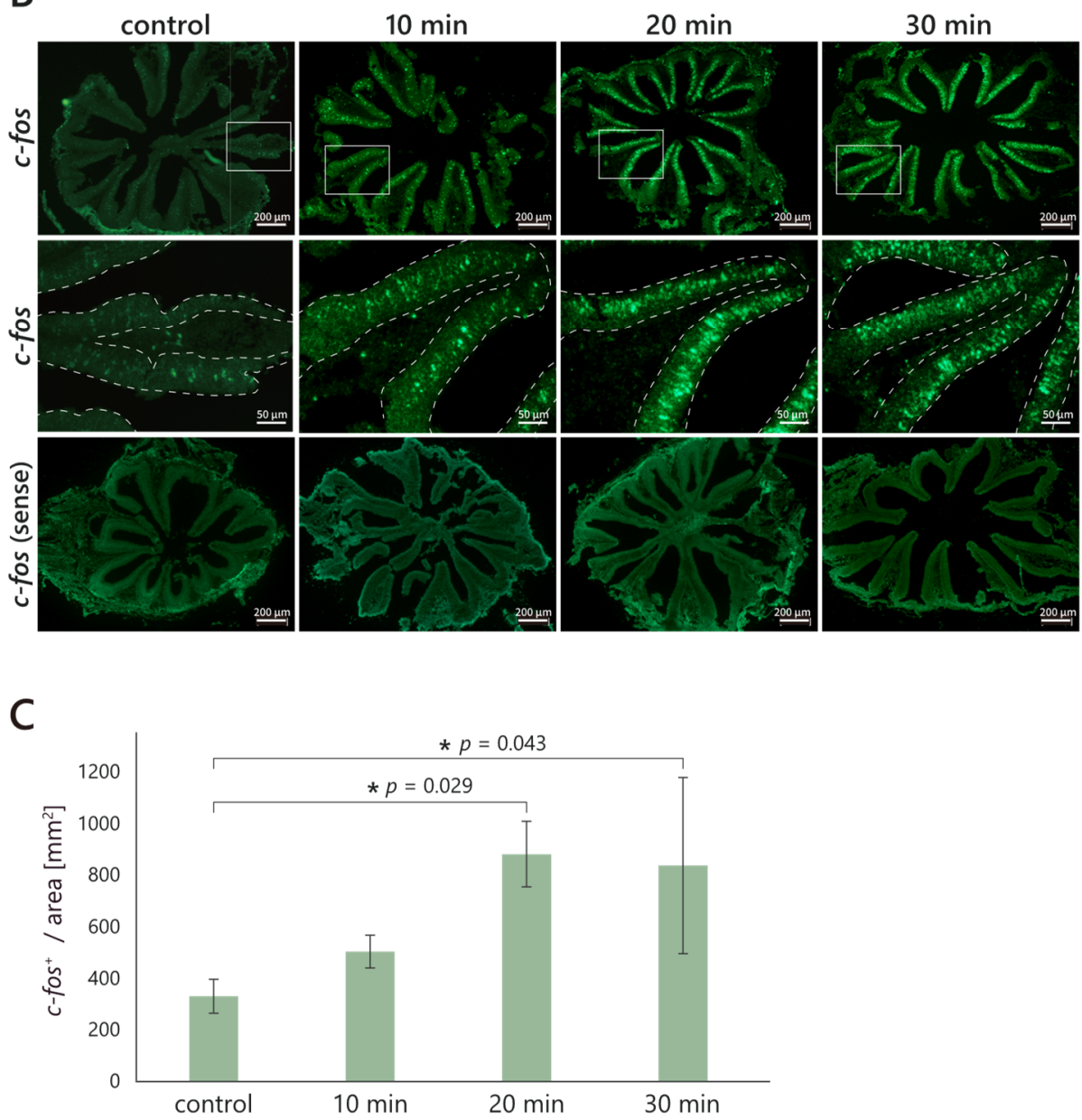

Figure 2. $C$-fos expression is robustly induced in olfactory epithelium (OE) by exposure

to food extraction. Cichlid was exposed to water (control) or food extraction (final concentration: $9.5 \mathrm{mg} / \mathrm{L}$ ). (A) In situ hybridization with cRNA probes for $c$-fos, $c$-jun, egrl, junb, or fral. The dotted line represents the outline of the OE. (B) In situ hybridization with cRNA probes for c-fos. The vertical columns represent the length of time between odorant exposure and ice anesthesia. The middle panels represent the magnified image of the box in the upper panel. (C) Bar plot of the density of $c-f o s^{+}$(three individuals each, five sections per individual; Tukey-Kramer test). ${ }^{*} p<0.05$. All data are shown as mean \pm SEM. 


\section{Neural response of microvillous neurons}

Next, we tested the neural response of microvillous neurons, which are expected to be dominated by V2R-expressing neurons (Supplementary Figure 1; Hansen et al., 2004; Sato et al., 2005), against four odorants: the mixture of 20 proteinogenic amino acids (final concentration at $2 \mu \mathrm{M}$ each), food extractions, male urine, and the mixture of three conjugated steroids (final concentration at $33 \mathrm{nM}$ each). Exposure to each of the four odorants significantly increased the number of $c$-fos-expressing neurons compared with the control with stronger intensity $(\mathrm{n}=4 ; p=0.047, p=0.035, p=0.024$, $p=0.043$; Welch's $t$-test, Figure 3A, B, Supplementary Table 2). We also calculate the colocalization rate of $\operatorname{Trpc} 2$, which is a marker gene of microvillous neurons (Sato et al., 2005), among c-fosexpressing neurons. It became the highest when exposed to amino acids (55\%) and was significantly higher than when exposed to male urine or conjugated steroids $\left(p=0.0080, p=6.1 \times 10^{-4}\right.$; Student's $t$-test; Figure 3C, Supplementary Table 2). It also became high when exposed to food extraction (Figure 3C). Alternatively, it became the lowest when exposed to conjugated steroids, a putative pheromone in cichlid (Cole and Stacey, 2006; Keller-Costa et al., 2014) and was significantly lower than when exposed to amino acids, food extraction, or male urine $\left(p=6.1 \times 10^{-4}, p=0.0095\right.$, $p=0.022$; Student's $t$-test; Figure 3C). 
A
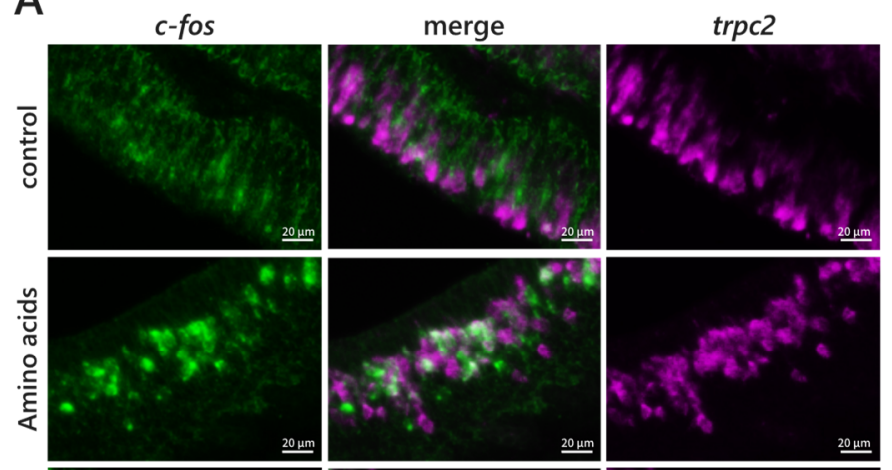
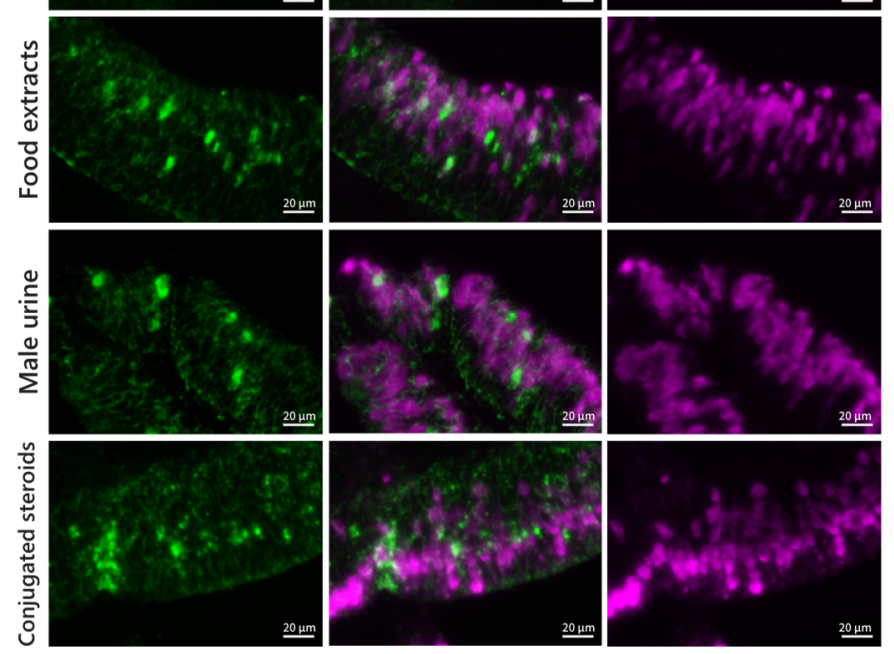

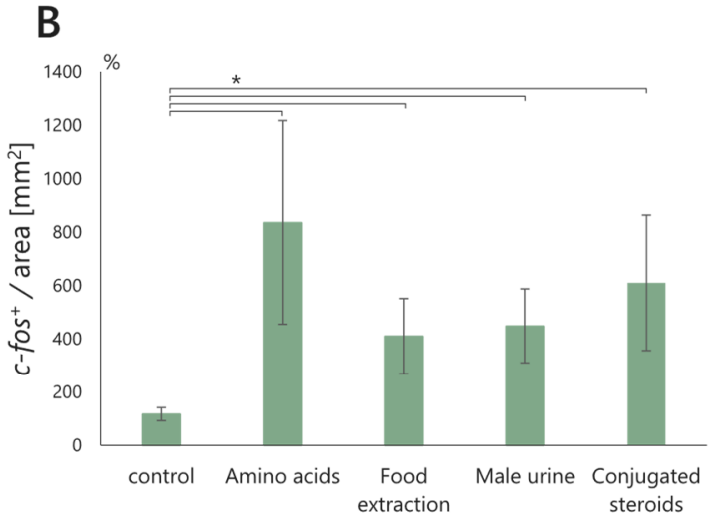

C

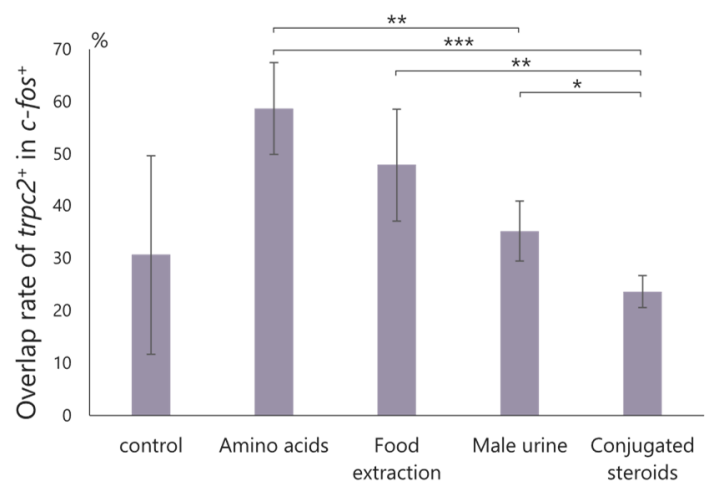

Figure 3. Response of microvillous neurons. (A-C) Double in situ hybridization with cRNA probes for $c$-fos (green) and TrpC2 (magenta) of olfactory epithelium sections of cichlid exposed to water (control), amino acids (final concentration: $2 \mu \mathrm{M}$ each), food extraction (final concentration: $9.5 \mathrm{mg} / \mathrm{L}$ ), male urine (final concentration: 6000-fold dilution), or conjugated steroids (final concentration: $33 \mathrm{nM}$ ). (B) Bar plot of the density of $c-f o s^{+}$(four individuals each, five sections per individual; Welch's $t$-test). (C) Bar plot of overlap rate of $\operatorname{TrpC} 2^{+}$in $c-f o s^{+}$(four individuals each, five sections per individual; Welch's $t$-test, Student's $t$-test). ${ }^{*} p<0.05,{ }^{*} p<0.01,{ }^{* * *} p<0.001$. All data are shown as mean \pm SEM. 


\section{Neural response of Vomeronasal type-2 receptor-expressing neurons to amino acid}

To test the hypothesis that fish receive amino acid via V2R receptors (Koide et al., 2009; DeMaria et al., 2013), we next exposed cichlid to amino acids and examined the response of $V 2 R$-expressing neurons. East African cichlids experienced a lineage-specific expansion in the $V 2 R$ multigene family and possessed 61 intact $V 2 R$ genes, one of the largest among teleost (Nikaido et al., 2013). Sixty-one genes comprise 13 subfamilies (Supplementary Figure 2). Within these 13 subfamilies, four subfamilies $(4,8,14$, and 16) have expanded the number of genes by tandem duplication. We first exposed cichlid to a mixture of 20 amino acids (final concentration at $2 \mu \mathrm{M}$ each) and tested the response of these four subfamilies $(4,8,14$, and 16) plus subfamily $2-1,7-1$ as a single-copy subfamily (Figure 4A, B, Supplementary Table 2). The responding rate was calculated from the colocalization rate of $c$-fos-expressing neurons among $V 2 R$-expressing neurons. In support of the hypothesis that fish receive amino acid via V2R receptors, relatively more fraction responded in subfamily 14, 16 (28\%/16\%; Figure 4A, B), and intermediate value of fraction responded in subfamily 2/7 (8.8\%; Figure 4A, B). Alternatively, only a small number of subfamily 4/8-expressing neurons responded to amino acids (3.6\%/0.9\%; Figure 4A, B). To determine which amino acid does V2R subfamily 14 and 16 receive, we exposed cichlid to four groups of amino acids: A, including nonpolar or neutral amino acids (Gly, Ala, Ser, Pro, and Thr); B, including aromatic or carbamic amino acid (Phe, Tyr, Trp, His, Asn, and Gln); C, including branched or sulfur-containing amino acids (Val, Ile, Leu, Met, and Cys); and D, including charged amino acids (Arg, Lys, Asp, and Glu) (final concentration at $2 \mu \mathrm{M}$ each). This grouping is based on electrical properties and the cluster analysis of goldfish odorant-induced activity patterns (Friedrich and Korsching, 1997). High rate (16\%) of V2R subfamily 14-expressing neurons responded with stronger intensity to amino acids D, including charged amino acids (Figure 4C, D, Supplementary Table 2). The other amino acid groups also responded in subfamily 14-expressing neurons, although the responding rate was much lower. To further narrow down the amino acids, which made a response in subfamily 14-expressing neurons, 
we exposed cichlid to individual amino acids and found that basic amino acid, especially arginine (final concentration at $10 \mu \mathrm{M}$ ), makes response (46\%; Figure 4C, D). We further tested the response to arginine of three single copies in subfamily 14 , which are 14-1, 14-2, and 14-6. Respectively, they responded $0 \%, 28 \%$, and 9.1\% (Figure 4E, F, Supplementary Table 2). Alternatively, subfamily 16expressing neurons most responded to amino acids group $\mathrm{C}$, although the rate was not high as subfamily 14-expressing neurons, which were exposed to group D (9.2\%; Figure 4D, Supplementary Figure 3A). We also tested the response to amino acids group $\mathrm{C}$ of three single copies in subfamily 16, which are 16-1, 16-3, and 16-6. However, no colocalization with $c$-fos was observed in any copy (Supplementary Figure 3B). 
bioRxiv preprint doi: https://doi.org/10.1101/2021.05.25.445711; this version posted July 12, 2021. The copyright holder for this preprint

(which was not certified by peer review) is the author/funder, who has granted bioRxiv a license to display the preprint in perpetuity. It is made available under aCC-BY 4.0 International license.

A

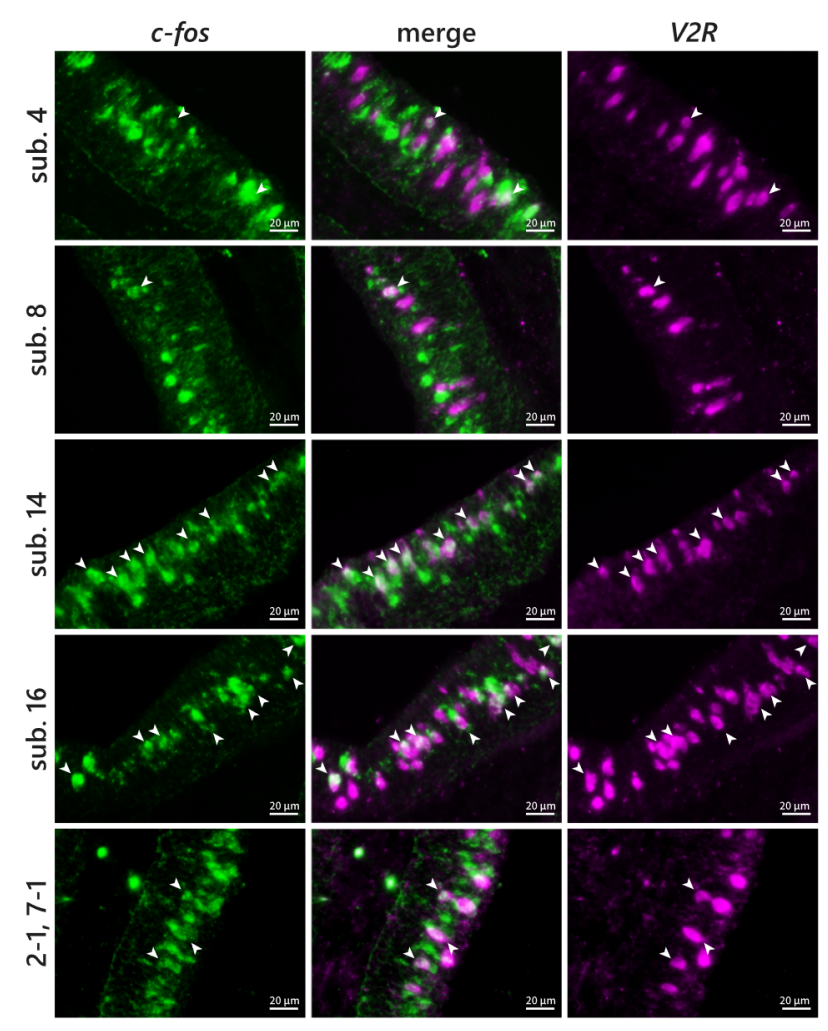

B

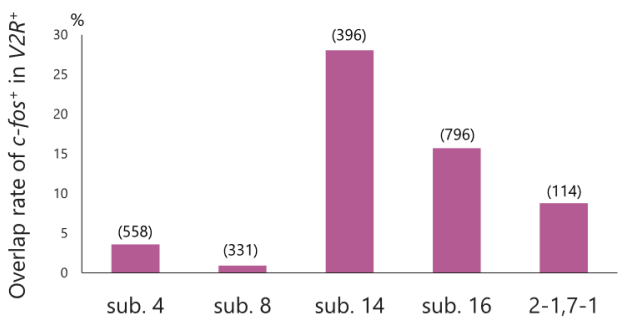

D

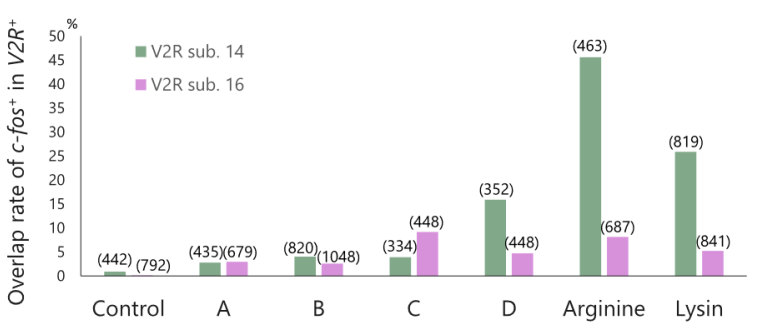

$\mathrm{F}$

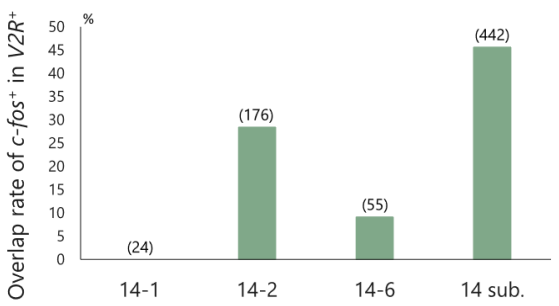

C
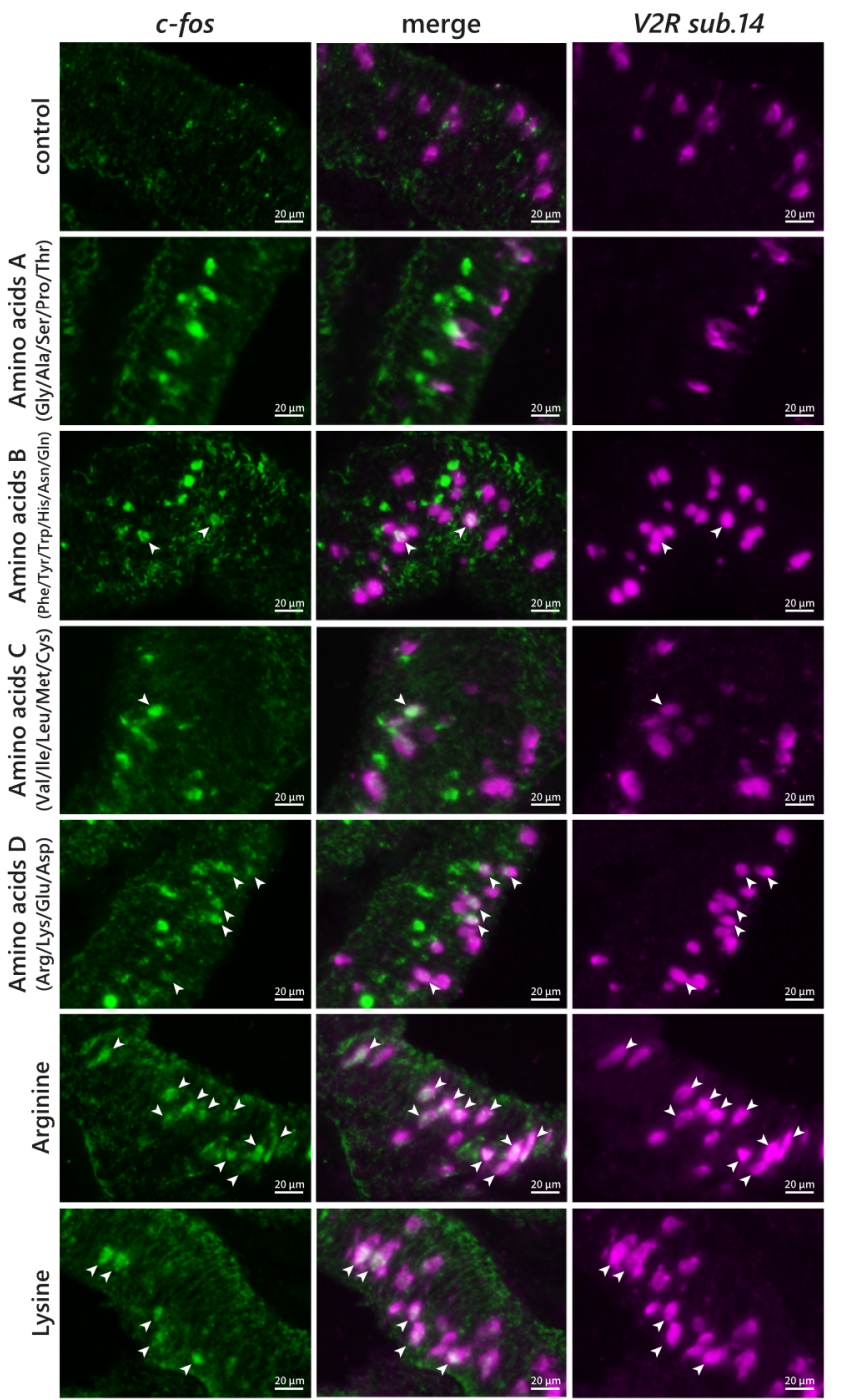

$E$

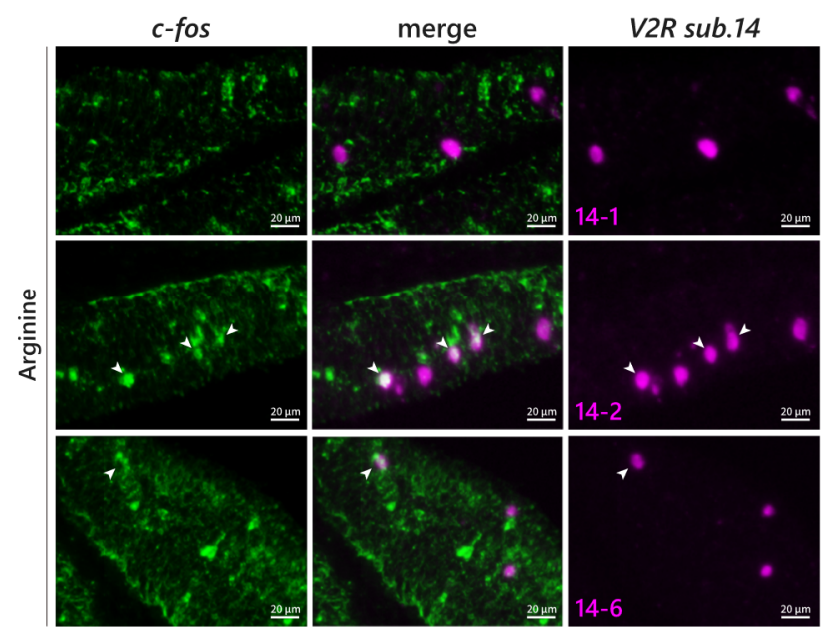


Figure 4. Response of V2R receptor to amino acids. Double in situ hybridization with cRNA probes for $c$-fos (green) and $V 2 R$ (magenta) of olfactory epithelium (OE) section exposed to amino acids. (A, C, E) Representative image. Arrowheads represent $c$-fos and $V 2 R$ colocalization. (B, D, F) Bar plot of overlap rate of $c-f o s^{+}$in $V 2 R^{+}$(one individual each). The numbers in the brackets represent the number of $V 2 R^{+}$counted in a single section. $(\mathbf{A}, \mathbf{B})$ OE section of cichlid exposed to amino acids (final concentration: $2 \mu \mathrm{M}$ each). Each probe is identical above $80 \%$ to all copies in each subfamily. (C, D) OE section of cichlid exposed to four groups of amino acids (A: Gly, Ala, Ser, Pro, Thr; B: Phe, Tyr, Trp, His, Asn, Gln; C: Val, Ile, Leu, Met, Cys; D: Arg, Lys, Asp, Glu; final concentration: $2 \mu \mathrm{M}$ each), arginine (final concentration at $10 \mu \mathrm{M}$ ) or lysine (final concentration at $10 \mu \mathrm{M}$ ). (E, F) OE section of cichlid exposed to arginine. (E) The upper image for 14-1, the middle image for 14-2, the bottom image for 14-6. 14-1, 14-2, and 14-6 belong to the V2R subfamily 14.

\section{Neural response of V1R-expressing neurons to odorants}

Finally, we tested the response of $V 1 R$-expressing neurons. We first test the response to the mixture of proteinogenic amino acids, food extraction, male urine, and the mix of three conjugated steroids using probes for the mixture of $6 V 1 R$ (Figure 5D, Supplementary Table 2). V1Rs-expressing neurons responded the most to male urine (24\%; Figure 5C, D). We next tested the response to male urine of each $6 V 1 R$ s and found $V 1 R 2$ and $V 1 R 5$-expressing neurons were responding (29\%, 40\%; Figure 5E, F, G). Additionally, we tested the response of V1R2-expressing neurons to 4HPAA and LCA, which are the candidate of the ligand of zebrafish V1R2 (Behrens et al., 2014; Cong et al., 2019). Many $V 1 R 2$-expressing neurons responded to $10 \mu \mathrm{M}$ 4HPAA (42\%), and a relatively large number also responded to $20 \mu \mathrm{M}$ LCA (17\%) (Figure 5E, G, Supplementary Table 2). 

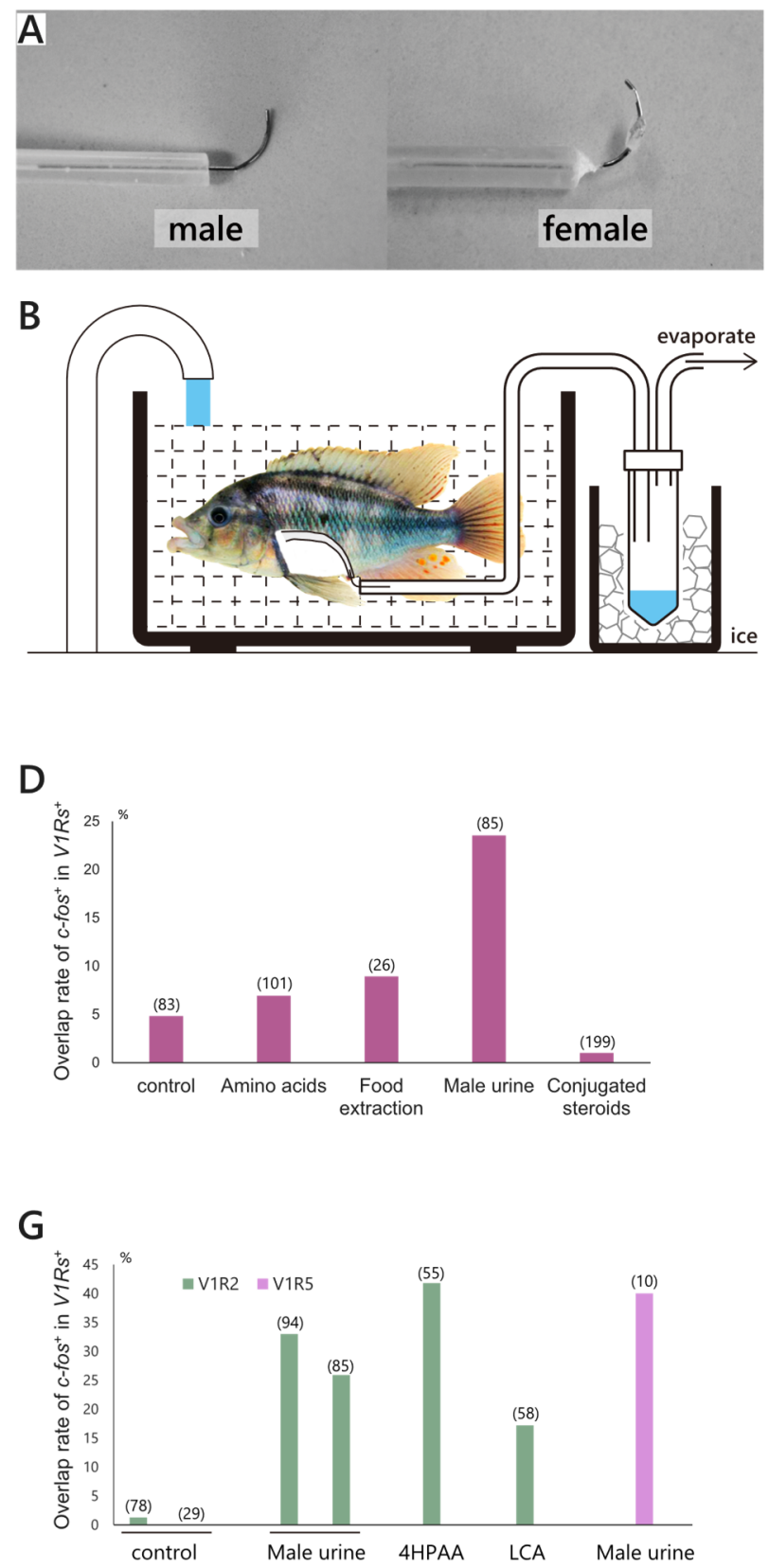

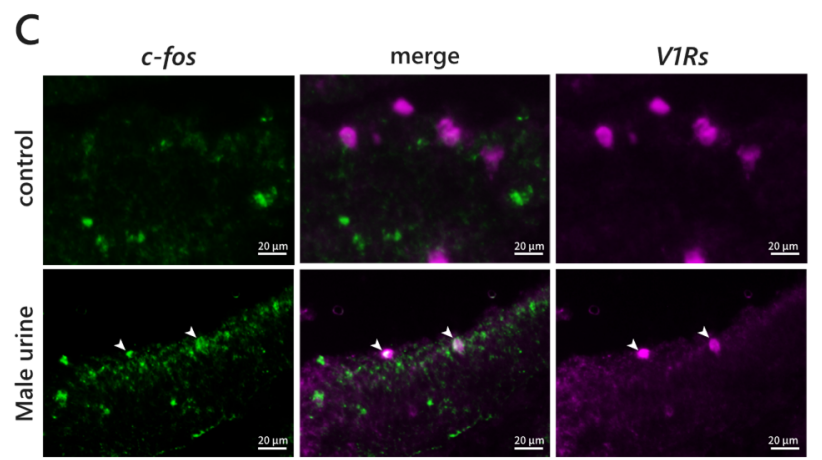

$\mathrm{E}$
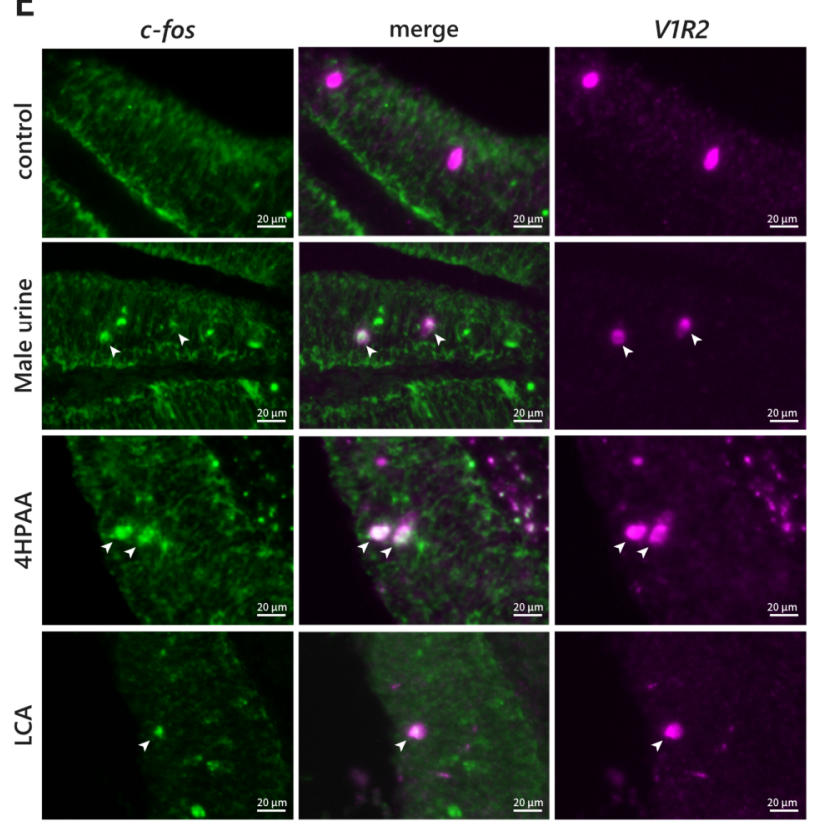

$\mathrm{F}$

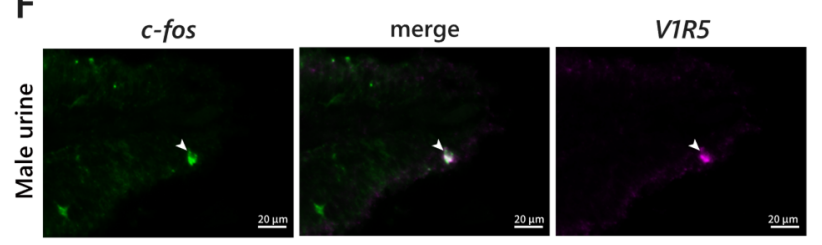

Figure 5. Response of V1R receptor. (A) The catheter was used for urine collection. These catheters have a hole in the side near the tip of the needle to prevent clogging. The catheter for females has a silicone plug attached to it. (B) Schematic drawing of urine collection. (C-F) Double in situ hybridization with cRNA probes for $c$-fos (green) and V1R (magenta) of olfactory epithelium section. (C, E, F) Representative image. Arrowheads represent $c$-fos and $V 1 R$ colocalization. (D, G) Bar plot of overlap rate of $\mathrm{f} c-f_{o s}{ }^{+}$in $V 1 R^{+}$(1 individual each). The numbers in the brackets represent the number of $V 1 R^{+}$counted in a single section. (C, D) Response of V1Rs (V1R1-6) receptor to amino acids (final concentration: $2 \mu \mathrm{M}$ each), food extraction (final concentration: $9.5 \mathrm{mg} / \mathrm{L}$ ), male urine (final concentration: 6000-fold dilution), or conjugated steroids (final concentration: $33 \mathrm{nM}$ ). (E) Response of V1R2 receptor to male urine (final concentration: 6000-fold dilution), 4HPAA (final 
bioRxiv preprint doi: https://doi.org/10.1101/2021.05.25.445711; this version posted July 12, 2021. The copyright holder for this preprint (which was not certified by peer review) is the author/funder, who has granted bioRxiv a license to display the preprint in perpetuity. It is made available under aCC-BY 4.0 International license.

concentration: $10 \mu \mathrm{M}$ ), or LCA (final concentration: $10 \mu \mathrm{M}$ ). (F) Response of V1R5 receptor to male urine (final concentration: 6000-fold dilution). 


\section{Discussion}

Here, we established a method to detect biological-derived neural responses from OE of East African cichlid via in situ hybridizations of $c$-fos and showed different neural responses to each odorant stimuli. We first identified the most suitable neural activity marker gene as c-fos. Egrl, another major marker gene for neural activity (Isogai et al., 2011), was reported to be helpful for an active marker of the cichlid brain (Burmeister and Fernald, 2005) but did not show upregulation in OE. $C$ fos-expressing neurons were significantly increased $20 \mathrm{~min}$ after exposure to food extraction. Also, the intensity was stronger after $20 \mathrm{~min}$. Hence, we concluded that $20 \mathrm{~min}$ is the best time between exposure and ice anesthesia for detecting olfactory response.

\section{V2R-expressing neuron responded to amino acids}

The rate of microvillous neurons (TrpC2-expressing neurons) among the $c$-fos-expressing neurons was highest when exposed to amino acids and high when exposed to food extract. Because microvillous neurons are expected to be dominated by $V 2 R$-expressing neurons since $V 1 R$ s are sparsely expressed (Ota et al., 2012; Supplementary Figure 1A), this result suggests that cichlids receive amino acids in food via $\mathrm{V} 2 \mathrm{R}$ receptors. This is consistent with the hypothesis that fish receive amino acids via V2R receptors (Koide et al., 2009; DeMaria et al., 2013). Alternatively, similar to some electrophysical research (Sato and Suzuki, 2001; Hansen et al., 2003; Sato and Sorensen, 2018) that showed that ciliated neurons also respond to amino acids, $45 \%$ c-fos-expressing neurons were not colabeled with $\operatorname{Trp} C 2$ when exposed to amino acids indicating that the rest $c$-fosexpressions were in ciliated neurons. The function of amino acid reception of ciliated neurons is unknown, but at least, V2R receptors are expected to trigger feeding behavior by receiving amino acids (Koide et al., 2009).

Next, we tested the response of individual subfamilies of V2R receptors to amino acids. East African cichlids have 61 copies of $V 2 R$, which is one of the largest numbers among teleosts. 
Although fish V2R receptors are shown to receive amino acids (Koide et al., 2009; DeMaria et al., 2013), it is interesting that cichlid has $V 2 R$ copies far more than the number of proteinogenic amino acids. We showed that subfamilies 4- and 8-expressing neurons did not respond to proteinogenic amino acids. This indicates that these V2R receptors receive other chemicals, such as nonproteinogenic amino acids and peptides. Kynurenine is one example of nonproteinogenic amino acid that masu salmon receive as a sex pheromone (Yambe et al., 2006). Mouse V2R receptors recognize peptides (Kimoto et al., 2005), and stickleback and zebrafish receive 9-mer MHC peptides via OE (Milinski et al., 2005; Hinz et al., 2013). These chemicals are possibly playing a role other than foraging. V2R subfamily 9 are suggested to relate to fright reaction in Ostariophysan fishes (Yang et al., 2019). Furthermore, peptides are more suitable for species-specific odor since peptides can be more variable than single amino acids by combining several amino acids. Within teleost $V 2 R \mathrm{~s}$, subfamilies 4 and 16 are independently diversified in several lineages (Nikaido et al., 2013), so that these subfamilies possibly receive species-specific odor. V2R subfamily 4 and at least three copies of V2R subfamily 16 only marginally responded to proteinogenic amino acids (Figure 4B; Supplementary Figure 3B). These V2R receptors possibly receive nonproteinogenic amino acids or peptides.

Also, the $V 2 R$ gene cluster is adjacent to neprilysin, which is encoding metallopeptidase, suggesting that neprilysin possibly produce degraded peptides received by $V 2 R$-expressing neurons (Hashiguchi and Nishida, 2006; Johnstone et al., 2009; Nikaido et al., 2013). We confirmed that neprilysin is expressed in the cichlid OE (Supplementary Figure 4). Most neprilysin was expressed in cells in the basal region of $\mathrm{OE}$. These cells likely excrete the free enzymatically active domain of neprilysin. Furthermore, some neprilysin colocated with $\operatorname{TrpC} 2$, which suggests that the V2R receptor receives proximally degraded peptides.

We also showed that among the three copies in subfamily 14 , explicitly expanded in a cichlid, one copy was receptive to arginine. One was slightly receptive, and one was unreceptive (Figure 4E, F). Moreover, we showed that subfamily 16 also expanded and responded to amino acids $\mathrm{C}$, whereas the 
three copies in subfamily 16 did not respond to amino acids C (Supplementary Figure 3B). These results suggest that copy expansion of cichlid $V 2 R$ led to increasing variation of receivable odorants via ligand differentiation. Our previous study also supported this hypothesis that the residues putatively related to ligand selectivity in cichlid-specifically expanded subfamilies were much diverse than that of whole teleost (Nikaido et al., 2013).

\section{Possible role of $\mathrm{V} 1 \mathrm{R} 2$ as a fundamental pheromone receptor that is common across teleost}

Finally, we tested the response of putative pheromone receptor V1R (Behrens et al., 2014). V1Rexpressing neurons most responded to male urine (24\%). This suggests that V1R receptors relate to social interaction. Conversely, V1R-expressing neurons did not respond to conjugated steroids, putative pheromones of cichlid (Cole and Stacey, 2006). Since conjugated steroids made less response of microvillous neurons (Figure 3C), which indicate that ciliated neurons receive them, they might be received via OR receptor or TAAR receptor.

We further tested every six V1R receptors and found that V1R2- and V1R5-expressing neurons responded to male urine (Figure 5E, F). Although V1R receptors other than V1R2 and V1R5 did not respond to urine, they might be responsible for other things such as female urine and feces. Another possibility is that it is used to find food since $9 \%$ of expressing neurons responded to food extract (Figure 5D).

We finally showed that V1R2-expressing neurons responded to 4HPAA and LCA (Figure 5E). Previous research also reported that cultured cells expressing zebrafish V1R2 responded to 4HPAA and bile acids (Behrens et al., 2014; Cong et al., 2019). Because previous research showed that exposure to 4HPAA induces spawning of zebrafish (Behrens et al., 2014), our preliminary experiments confirmed that 4HPAA exists in the cichlid urine and V1R2 receptor might be a fundamental pheromone (= 4HPAA) receptor, which is common across teleost. Additionally, of the two distinct types of V1R2 alleles (Nikaido et al., 2014) in East African cichlids, the individuals used 
in this study had the ancestral allele. Further investigation of the function of the other derivative allele might help to understand the impact of the V1R2 receptor on adaptive radiation in cichlid via assortative mating. 


\section{Funding}

This work was supported by JSPS KAKENHI [grant numbers 20H03307 and 20KK0167 to M.N.] and the Sasakawa Scientific Research Grant from The Japan Science Society [grant number 20214099 to R.K.].

\section{Conflict of interest}

The authors do not have any conflicts of interest.

\section{Acknowledgements}

We thank Mitsuto Aibara for collecting cichlid in the field research in Tanzania, Tatsuki Nagasawa for the advice in experiment, and the Biomaterials Analysis Division, Tokyo Institute of Technology for sequencing. 


\section{Reference}

Behrens, M., Frank, O., Rawel, H., Ahuja, G., Potting, C., Hofmann, T., Meyerhof, W., and Korsching, S.I. 2014. ORA1, a zebrafish olfactory receptor ancestral to all mammalian V1R genes, recognizes 4-hydroxyphenylacetic acid, a putative reproductive pheromone. J Biol Chem. 289:19778-19788.

Buck, L., and Axel, R. 1991. A Novel Multigene Family May Encode Odorant Receptors: A Molecular Basis for Odor Recognition.

Burmeister, S.S., and Fernald, R.D. 2005. Evolutionary conservation of the Egr-1 immediate-early gene response in a teleost. J Comp Neurol. 481:220-232.

Cole, T.B., and Stacey, N.E. 2006. Olfactory responses to steroids in an African mouth-brooding cichlid, Haplochromis burtoni (Günther). J Fish Biol. 68:661-680.

Cong, X., Zheng, Q., Ren, W., Chéron, J.-B., Fiorucci, S., Wen, T., Zhang, C., Yu, H., Golebiowski, J., and Yu, Y. 2019. Zebrafish Olfactory Receptors ORAs Differentially Detect Bile Acids and Bile Salts. J Biol Chem. jbc.RA118.006483.

DeMaria, S., Berke, A.P., Name, E. Van, Heravian, A., Ferreira, T., and Ngai, J. 2013. Role of a Ubiquitously Expressed Receptor in the Vertebrate Olfactory System. J Neurosci. 33:1523515247.

Dulac, C., and Axel, R. 1995. A novel family of genes encoding putative pheromone receptors in mammals. Cell. 83:195-206.

Fatsini, E., Carazo, I., Chauvigné, F., Manchado, M., Cerdà, J., Hubbard, P.C., and Duncan, N.J. 2017. Olfactory sensitivity of the marine flatfish Solea senegalensis to conspecific body fluids. J Exp Biol. 220:2057-2065.

Friedrich, R.W., and Korsching, S.I. 1997. Combinatorial and chemotopic odorant coding in the zebrafish olfactory bulb visualized by optical imaging. Neuron. 18:737-752.

Hansen, A., Anderson, K.T., and Finger, T.E. 2004. Differential distribution of olfactory receptor neurons in goldfish: Structural and molecular correlates. J Comp Neurol. 477:347-359.

Hansen, A., Rolen, S.H., Anderson, K., Morita, Y., Caprio, J., and Finger, T.E. 2003. Correlation between Olfactory Receptor Cell Type and Function in the Channel Catfish. J Neurosci. 23:9328-9339.

Hara, T.J. 2006. Feeding behaviour in some teleosts is triggered by single amino acids primarily through olfaction. J Fish Biol. 68:810-825.

Hashiguchi, Y., and Nishida, M. 2006. Evolution and origin of vomeronasal-type odorant receptor gene repertoire in fishes. BMC Evol Biol. 13:1-13.

Herrada, G., and Dulac, C. 1997. A novel family of putative pheromone receptors in mammals with a topographically organized and sexually dimorphic distribution. Cell. 90:763-773.

Hinz, C., Namekawa, R., Behrmann-Godel, J., Oppelt, C., Jaeschke, A., Müller, A., Friedrich, R.W., and Gerlach, G. 2013. Olfactory imprinting is triggered by MHC peptide ligands. Sci Rep. 3:1- 
9.

Huertas, M., Hagey, L., Hofmann, A.F., Cerdà, J., Canário, A.V.M., and Hubbard, P.C. 2010. Olfactory sensitivity to bile fluid and bile salts in the European eel (Anguilla anguilla), goldfish (Carassius auratus) and Mozambique tilapia (Oreochromis mossambicus) suggests a "broad range" sensitivity not confined to those produced by conspecifics a. J Exp Biol. 213:308-317.

Hussain, A., Saraiva, L.R., Ferrero, D.M., Ahuja, G., Krishna, V.S., Liberles, S.D., and Korsching,

S.I. 2013. High-affinity olfactory receptor for the death-associated odor cadaverine. Proc Natl Acad Sci U S A. 110:19579-19584.

Hussain, A., Saraiva, L.R., and Korsching, S.I. 2009. Positive Darwinian selection and the birth of an olfactory receptor clade in teleosts. Proc Natl Acad Sci U S A. 106:4313-4318.

Isogai, Y., Si, S., Pont-Lezica, L., Tan, T., Kapoor, V., Murthy, V.N., and Dulac, C. 2011. Molecular organization of vomeronasal chemoreception. Nature. 478:241-245.

Johnstone, K.A., Ciborowski, K.L., Lubieniecki, K.P., Chow, W., Phillips, R.B., Koop, B.F., Jordan, W.C., and Davidson, W.S. 2009. Genomic organization and evolution of the vomeronasal type 2 receptor-like (OlfC) gene clusters in atlantic salmon, salmo salar. Mol Biol Evol. 26:1117-1125.

Keller-Costa, T., Canário, A.V.M., and Hubbard, P.C. 2015. Chemical communication in cichlids: A mini-review. Gen Comp Endocrinol. 221:64-74.

Keller-Costa, T., Hubbard, P.C., Paetz, C., Nakamura, Y., Silva, J.P. Da, Rato, A., Barata, E.N., Schneider, B., and Canario, A.V.M. 2014. Identity of a tilapia pheromone released by dominant males that primes females for reproduction. Curr Biol. 24:2130-2135.

Kimoto, H., Haga, S., Sato, K., and Touhara, K. 2005. Sex-specific peptides from exocrine glands stimulate mouse vomeronasal sensory neurons. Nature. 437:898-901.

Koide, T., Miyasaka, N., Morimoto, K., Asakawa, K., Urasaki, A., Kawakami, K., and Yoshihara, Y. 2009. Olfactory neural circuitry for attraction to amino acids revealed by transposon-mediated gene trap approach in zebrafish. Proc Natl Acad Sci U S A. 106:9884-9889.

Kozlov, A.M., Darriba, D., Flouri, T., Morel, B., and Stamatakis, A. 2019. RAxML-NG: A fast, scalable and user-friendly tool for maximum likelihood phylogenetic inference. Bioinformatics. 35:4453-4455.

Li, W., Sorensen, P.W., and Gallaher, D.D. 1995. The olfactory system of migratory adult sea lamprey (Petromyzon marinus) is specifically and acutely sensitive to unique bile acids released by conspecific larvae. J Gen Physiol. 105:569-587.

Liberles, S.D., and Buck, L.B. 2006. A second class of chemosensory receptors in the olfactory epithelium. Nature. 442:645-650.

Michel, W.C., and Lubomudrov, L.M. 1995. Specificity and sensitivity of the olfactory organ of the zebrafish, Danio rerio. J Comp Physiol A. 177:191-199.

Milinski, M., Griffiths, S., Wegner, K.M., Reusch, T.B.H., Haas-Assenbaum, A., and Boehm, T. 2005. Mate choice decisions of stickleback females predictably modified by MHC peptide ligands. Proc Natl Acad Sci U S A. 102:4414-4418. 
Miranda, A., Almeida, O.G., Hubbard, P.C., Barata, E.N., and Canário, A.V.M. 2005. Olfactory discrimination of female reproductive status by male tilapia (Oreochromis mossambicus). J Exp Biol. 208:2037-2043.

Nikaido, M., Ota, T., Hirata, T., Suzuki, H., Satta, Y., Aibara, M., Mzighani, S.I., Sturmbauer, C., Hagino-Yamagishi, K., and Okada, N. 2014. Multiple episodic evolution events in v1r receptor genes of East-African cichlids. Genome Biol Evol. 6:1135-1144.

Nikaido, M., Suzuki, H., Toyoda, A., Fujiyama, A., Hagino-Yamagishi, K., Kocher, T.D., Carleton, K., and Okada, N. 2013. Lineage-specific expansion of vomeronasal type 2 receptor-like (OlfC) genes in cichlids may contribute to diversification of amino acid detection systems. Genome Biol Evol. 5:711-722.

Oka, Y., Saraiva, L.R., and Korsching, S.I. 2012. Crypt neurons express a single v1r-related ora gene. Chem Senses. 37:219-227.

Ota, T., Nikaido, M., Suzuki, H., Hagino-Yamagishi, K., and Okada, N. 2012. Characterization of V1R receptor (ora) genes in Lake Victoria cichlids. Gene. 499:273-279.

Plenderleith, M., Oosterhout, C. Van, Robinson, R.L., and Turner, G.F. 2005. Female preference for conspecific males based on olfactory cues in a Lake Malawi cichlid fish. Biol Lett. 1:411-414.

Rolen, S.H., Sorensen, P.W., Mattson, D., and Caprio, J. 2003. Polyamines as olfactory stimuli in the goldfish Carassius auratus. J Exp Biol. 206:1683-1696.

Sato, K., and Sorensen, P.W. 2018. The chemical sensitivity and electrical activity of individual olfactory sensory neurons to a range of sex pheromones and food odors in the goldfish. Chem Senses. 43:249-260.

Sato, K., and Suzuki, N. 2001. Whole-cell Response Characteristics of Ciliated and Microvillous Olfactory Receptor Neurons to Amino Acids, Pheromone Candidates and Urine in Rainbow Trout. Chem Senses. 26:1145-1156.

Sato, Y., Miyasaka, N., and Yoshihara, Y. 2005. Mutually Exclusive Glomerular Innervation by Two Distinct Types of Olfactory Sensory Neurons Revealed in Transgenic Zebrafish. J Neurosci. 25:4889-4897.

Shoji, T., Yamamoto, Y., Nishikawa, D., Kurihara, K., and Ueda, H. 2003. Amino acids in stream water are essential for salmon homing migration. Fish Physiol Biochem. 28:249-251.

Sorensen, P.W., Hara, T.J., and Stacey, N.E. 1987. Extreme olfactory sensitivity of mature and gonadally-regressed goldfish to a potent steroidal pheromone, $17 \alpha, 20 \beta$-dihydroxy-4-pregnen3-one. J Comp Physiol A. 160:305-313.

Sorensen, P.W., Hara, T.J., Stacey, N.E., and Goetz, F.W. 1988. F Prostaglandins Function as Potent Olfactory Stimulants that Comprise the Postovulatory Female Sex Pheromone in Goldfish1. Biol Reprod. 39:1039-1050.

Sorensen, P.W., Pinillos, M., and Scott, A.P. 2005. Sexually mature male goldfish release large quantities of androstenedione into the water where it functions as a pheromone. Gen Comp Endocrinol. 140:164-175. 
Sorensen, P.W., and Sato, K. 2005. Second messenger systems mediating sex pheromone and amino acid sensitivity in goldfish olfactory receptor neurons. Chem Senses. 30 SUPPL.:315-316.

Stacey, N.E., Sorensen, P.W., Kraak, G.J. Van Der, and Dulka, J.G. 1989. Direct evidence that $17 \alpha, 20 \beta$-dihydroxy-4-pregnen-3-one functions as a goldfish primer pheromone: Preovulatory release is closely associated with male endocrine responses. Gen Comp Endocrinol. 75:62-70.

Suzuki, H., Nikaido, M., Hagino-Yamagishi, K., and Okada, N. 2015. Distinct functions of two olfactory marker protein genes derived from teleost-specific whole genome duplication Evolutionary ecology and behaviour. BMC Evol Biol. 15:1-13.

Valentinčič, T., Lamb, C.F., and Caprio, J. 1999. Expression of a reflex biting/snapping response to amino acids prior to first exogenous feeding in salmonid alevins. Physiol Behav. 67:567-572.

Verzijden, M.N., and Cate, C. Ten. 2007. Early learning influences species assortative mating preferences in Lake Victoria cichlid fish. Biol Lett. 3:134-136.

Wakisaka, N., Miyasaka, N., Koide, T., Masuda, M., and Hiraki-kajiyama, T. 2017. An Adenosine Receptor for Olfaction in Fish Article An Adenosine Receptor for Olfaction in Fish. Curr Biol. 27:1437-1447.e4.

Yabuki, Y., Koide, T., Miyasaka, N., Wakisaka, N., Masuda, M., Ohkura, M., Nakai, J., Tsuge, K., Tsuchiya, S., Sugimoto, Y., et al. 2016. Olfactory receptor for prostaglandin F2amediates male fish courtship behavior. Nat Neurosci. 19:897-904.

Yamamoto, Y., Hino, H., and Ueda, H. 2010. Olfactory Imprinting of Amino Acids in Lacustrine Sockeye Salmon. PLoS One. 5:e8633.

Yamamoto, Y., Shibata, H., and Ueda, H. 2013. Olfactory Homing of Chum Salmon to Stable Compositions of Amino Acids in Natal Stream Water. Zoolog Sci. 30:607.

Yambe, H., Kitamura, S., Kamio, M., Yamada, M., Matsunaga, S., Fusetani, N., and Yamazaki, F. 2006. 1-Kynurenine, an amino acid identified as a sex pheromone in the urine of ovulated female masu salmon. Proc Natl Acad Sci. 103:15370-15374.

Yambe, H., Shindo, M., and Yamazaki, F. 1999. A releaser pheromone that attracts males in the urine of mature female masu salmon. J Fish Biol. 55:158-171.

Yang, L., Jiang, H., Wang, Y., Lei, Y., Chen, J., Sun, N., Lv, W., Wang, C., Near, T.J., and He, S. 2019. Expansion of vomeronasal receptor genes (OlfC) in the evolution of fright reaction in Ostariophysan fishes. Commun Biol. 2.

Zhang, C., Brown, S.B., and Hara, T.J. 2001. Biochemical and physiological evidence that bile acids produced and released by lake char (Salvelinus namaycush) function as chemical signals. J Comp Physiol - B Biochem Syst Environ Physiol. 171:161-171. 


\section{Supplementary Data}

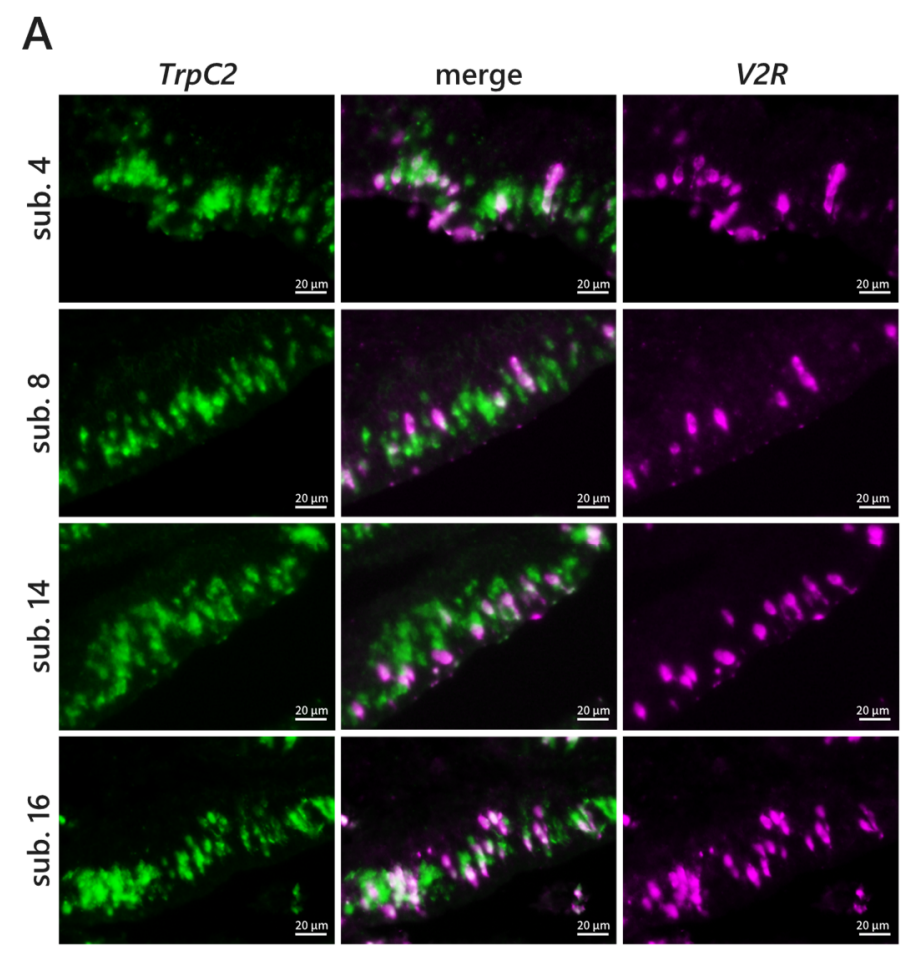

B

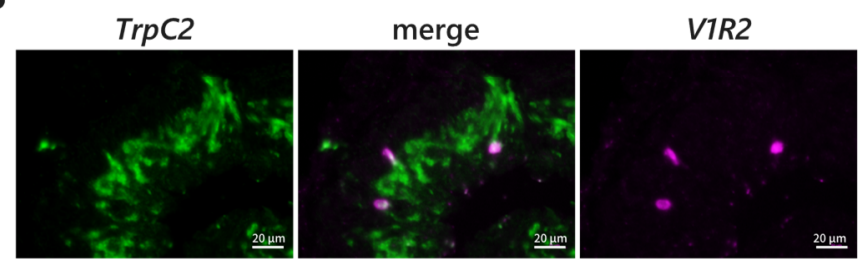

C

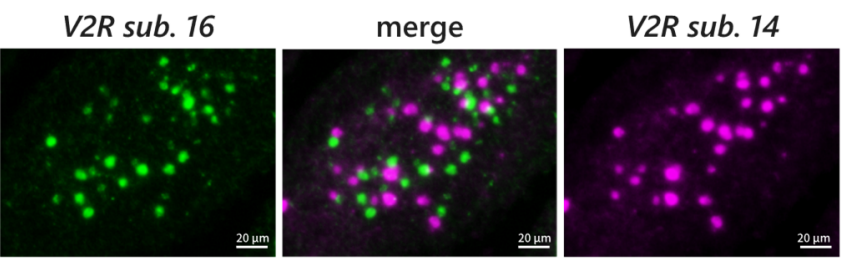

Supplementary Figure 1. Coexpression of TrpC2 and V2R or V1R. (A-B) Double in situ hybridization with cRNA probes for $\operatorname{Trp} C 2$ (green) and $V 2 R s$ (A; magenta) or V1R2 (B; magenta) of olfactory epithelium (OE) section. All V2Rs and V1R2 colocalized with TrpC2. (C) Double in situ hybridization with cRNA probes for $V 2 R$ sub. 16 (green) and V2R sub. 14 (magenta) of OE section. They are exclusively located with each other. 


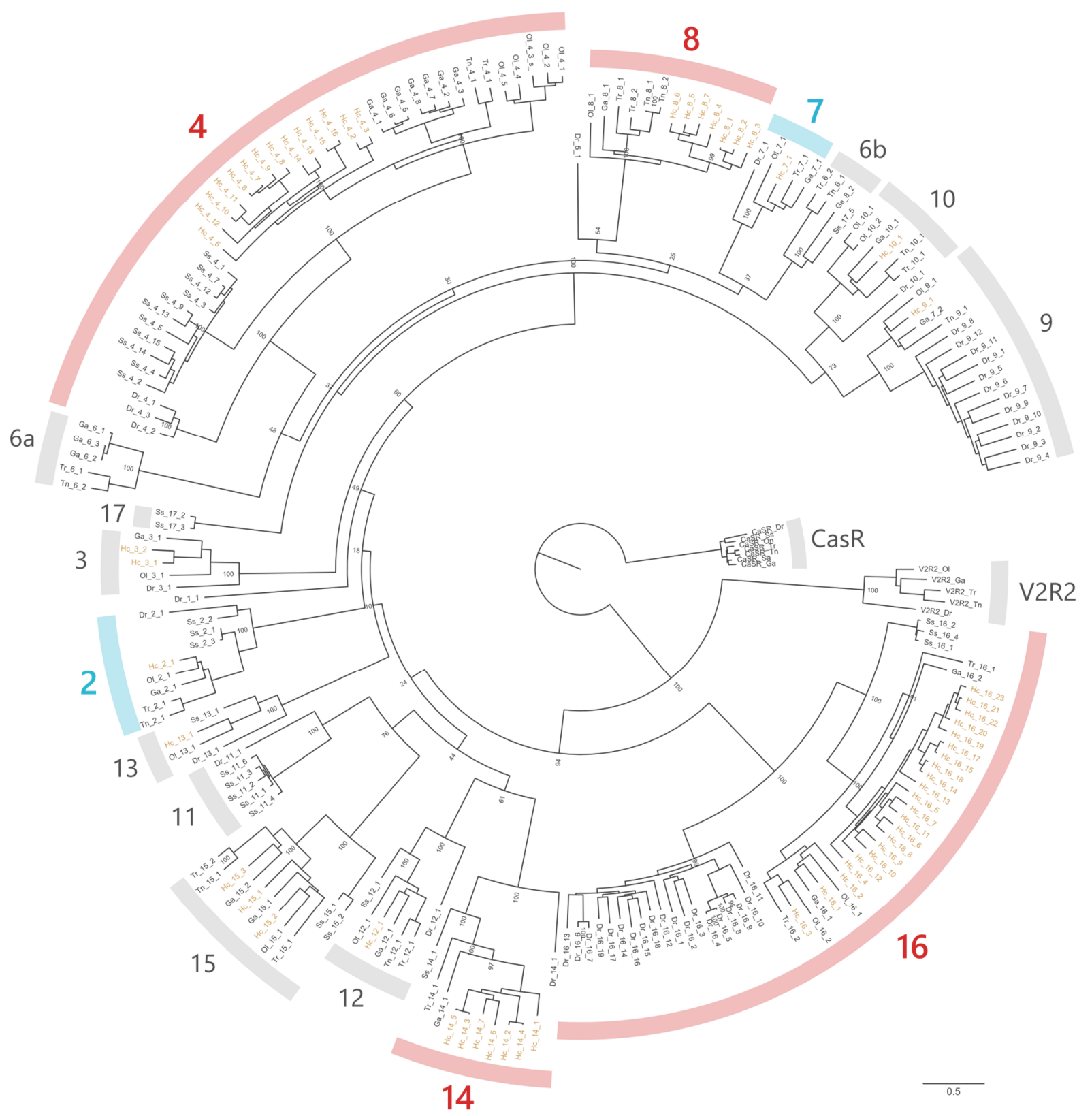

\section{Supplementary Figure 2. Maximum likelihood (ML) tree for $V 2 R$ genes of seven teleost}

fishes. All the amino acid sequences were collected from Nikaido et al. (2013). RAxML-NG (Kozlov et al., 2019) was used to construct an ML tree with 100 bootstrap replicates. Numbers close to the nodes are ML bootstrap percentages. Arcs represent each subfamily. Subfamilies used in this study were coloured red (expanded in cichlid) or blue (not expanded in cichlid). Sequences of cichlid are coloured orange. Hc: East African cichlid (Haplochromis chilotes); Dr: zebrafish (Danio rerio); Ss: Atlantic salmon (Salmo salar); Ga: three-spined stickleback (Gasterosteus aculeatus); Tr: fugu (Takifugu rubripes), Tn: green-spotted pufferfish (Tetraodon nigroviridis); Ol: medaka (Oryzias latipes). 


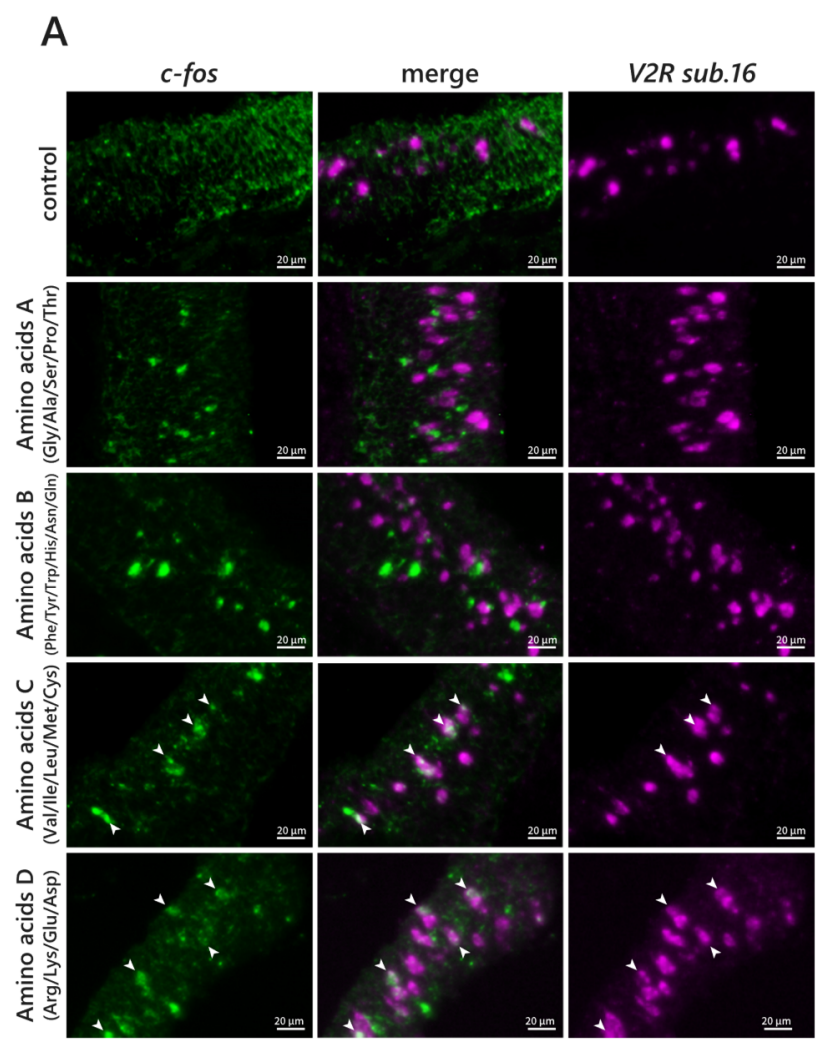

B

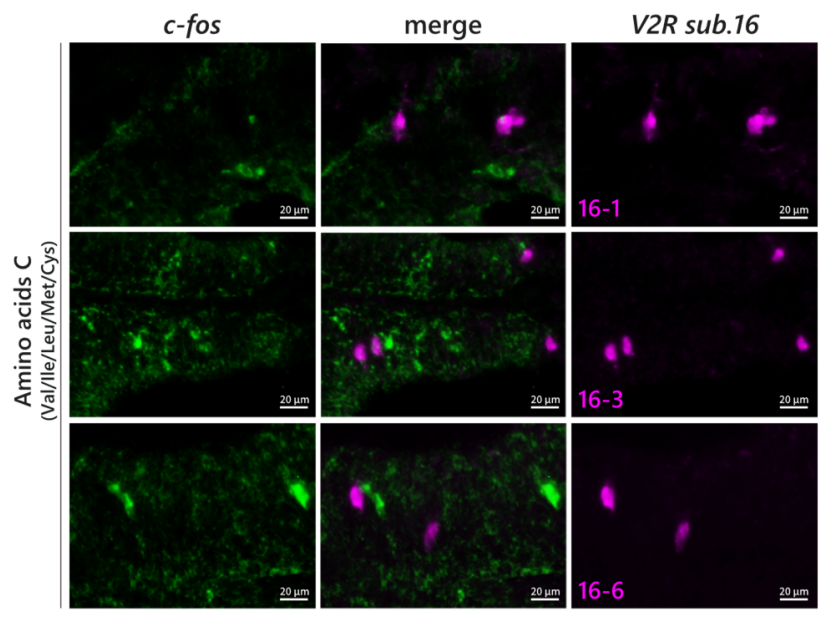

Supplementary Figure 3. Response of V2R sub. Sixteen receptors to amino acids. (A) Double in situ hybridization with cRNA probes for $c$-fos (green) and $V 2 R$ sub. 16 (magenta) of olfactory epithelium (OE) section exposed to four groups of amino acids (A: Gly, Ala, Ser, Pro, Thr; B: Phe, Tyr, Trp, His, Asn, Gln; C: Val, Ile, Leu, Met, Cys; D: Arg, Lys, Asp, Glu; final concentration: $2 \mu \mathrm{M}$ each), arginine (final concentration at $10 \mu \mathrm{M}$ ) or lysine (final concentration at $10 \mu \mathrm{M}$ ). (B) Double in situ hybridization with cRNA probes for $c$-fos (green) and $V 2 R$ 16-1/16-3/163 (magenta) of OE section exposed to amino acids group C (Val, Ile, Leu, Met, Cys; final concentration at $10 \mu \mathrm{M})$. Arrowheads represent colocalization. 


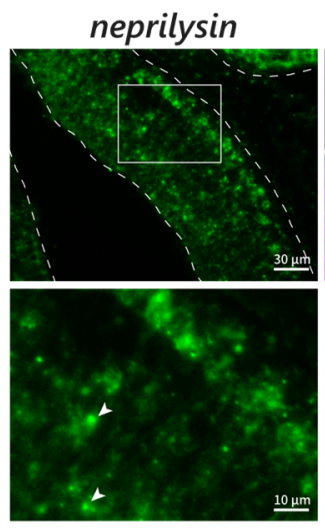

$$
\text { merge - DAPI }
$$

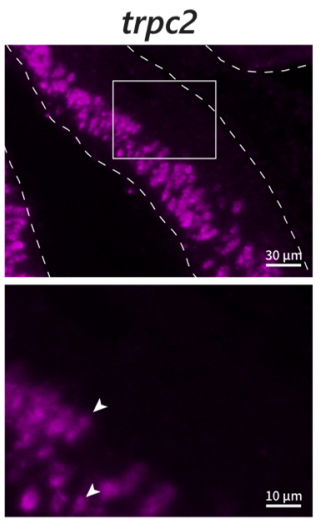

Supplementary Figure 4. Expression of neprilysin in OE. Double in situ hybridization with cRNA probes for neprilysin (green) and $\operatorname{TrpC} 2$ (magenta) of olfactory epithelium (OE) sections of cichlid. The middle panels represent the merged image of neprilysin and TrpC2 with DAPI (blue). The dotted line represents the outline of the OE. Neprilysin is primarily expressed in the basal region of $\mathrm{OE}$ except little in the middle region. The lower panels represent the magnified image of the box in the upper panel. Arrowheads represent the colocalization of neprilysin and $\operatorname{Trp} C 2$.

Supplementary Table 1. Primer list used in this study.

Supplementary Table 2. Summary of quantification data analyzed in this study. 